\title{
INFLUENCE OF ANNEALING CONDITIONS ON THE PHOTOELECTROCATALYTIC PERFORMANCE OF $\mathrm{WO}_{3}$ NANOSTRUCTURES
}

\author{
Roselló-Márquez, G. ; Fernández-Domene, R.M. ª; Sánchez-Tovar, R. a,b; García- \\ Antón, J.a \\ ${ }^{a}$ Ingeniería Electroquímica y Corrosión (IEC), Instituto Universitario de Seguridad \\ Industrial, Radiofísica y Medioambiental (ISIRYM), Universitat Politècnica de \\ València, Camino de Veras/n, 46022 Valencia, Spain. *jgarciaa@iqn.upv.es \\ ${ }^{b}$ Departmento de Ingeniería Química, Universitat de València, Av de les Universitats, \\ s/n, 46100 Burjassot, Spain
}

\begin{abstract}
Nanostructured $\mathrm{WO}_{3}$ photoanodes have been synthesized by electrochemical anodization under controlled hydrodynamic conditions in acidic media in the presence of $0.05 \mathrm{M} \mathrm{H}_{2} \mathrm{O}_{2}$. Subsequently, samples have been subjected to a thermal treatment (annealing) at different temperatures $\left(400^{\circ} \mathrm{C}, 500^{\circ} \mathrm{C}\right.$ and $\left.600^{\circ} \mathrm{C}\right)$ and under different gaseous atmospheres (air, $\mathrm{N}_{2}, \mathrm{Ar}$ ). The influence of these annealing conditions on the morphology, crystallinity, photoelectrochemical behavior and dopant chemistry of the different photoanodes has been investigated through Electronic Microscopy, Raman Spectroscopy, Photoelectrochemical Impedance Spectroscopy and Mott-Schottky analysis. In general, higher annealing temperatures resulted in samples with higher degrees of crystallinity, which in turn favored the transport of electron-hole pairs through the semiconducting photoanodes. Besides, an increase in annealing temperature implied higher densities of donor species within the samples structure, which can explain the observed enhancement in charge transfer. Annealing temperature was observed to have a more marked impact on the photoelectrocatalytic performance of $\mathrm{WO}_{3}$ nanostructures than the gaseous atmosphere.
\end{abstract}

Keywords: $\mathrm{WO}_{3}$ nanostructures, photoanode, anodization, annealing conditions, photoelectrochemical impedance spectroscopy (PEIS). 


\section{INTRODUCTION}

Tungsten oxide $\left(\mathrm{WO}_{3}\right)$ is considered as one of the most important photocatalytic materials due to its excellent properties such as its earth-abundance, its highly modifiable composition, high chemical stability in a range of moderate $\mathrm{pH}$ and excellent electrical conductivity [1-3], and its great variety of applications such as its use as a producer of clean energy. The global energy consumption is expected to increase even more during the next years as a result of the technological advances of society on a dayto-day basis. Nowadays, most of the consumed energy comes from fossil fuels [4] such as oil, coke and natural gas but they will end up being depleted in the future. Moreover, these fossil fuels are not sustainable, leading to the drastic climate change that is occurring through global warming, as well as generating other types of pollution. Then, there is a great need to find renewable and environmentally friendly energy sources to reduce the environmental impact of fossil fuels and the full cost that this impact entails.

$\mathrm{WO}_{3}$ is composed of units of perovskite, making it one of the most attractive candidates for its use in photoelectrocatalysis (PEC), since it can absorb up to $12 \%$ of the solar spectrum with a band gap $\left(E_{g}\right)$ between 2.5 and $2.8 \mathrm{eV}$, a moderate hole diffusion length $(\sim 150 \mathrm{~nm})$ compared to $\alpha-\mathrm{Fe}_{2} \mathrm{O}_{3}(2-4 \mathrm{~nm})$ and better electron transport $\left(\mathrm{ca} .12 \mathrm{~cm}^{2} \mathrm{~V}^{-1} \mathrm{~s}^{-}\right.$

$\left.{ }^{1}\right)$ compared to $\mathrm{TiO}_{2}\left(0.3 \mathrm{~cm}^{2} \mathrm{~V}^{-1} \mathrm{~s}^{-1}\right)$ [5-8]. In addition, $\mathrm{WO}_{3}$ is a n- type material, so it is used as a photoanode. It presents a high stability at low $\mathrm{pH}$ where the evolution of $\mathrm{H}_{2}$ happens more efficiently. As mentioned above, $\mathrm{WO}_{3}$ absorbs a greater part of the sunlight than $\mathrm{TiO}_{2}$ and shows higher photocurrent densities in a steady state since it has a higher incident photon to current efficiency (IPCE) than the $\mathrm{Fe}_{2} \mathrm{O}_{3}$. Therefore, $\mathrm{WO}_{3}$ is considered more appropriate than, for instance, $\mathrm{TiO}_{2}$ and $\mathrm{Fe}_{2} \mathrm{O}_{3}$ for PEC applications. However, this material exhibits high recombination of the photogenerated electron- 
holes during the PEC process, which is an inconvenient when PEC is carried out in practice [9].

The crystal structure of $\mathrm{WO}_{3}$ is based on an $\mathrm{ABO}_{3}$ perovskite structure with threedimensional networks where $\mathrm{WO}_{6}$ octahedra are shared in the corners. However, due to the distortions related to antiferroelectric displacements of the $\mathrm{W}$ atoms and the mutual rotation of the oxygen octahedra, the structure of $\mathrm{WO}_{3}$ shows significant differences from the ideal perovskite structure showing five stable phases in a range of temperature that goes from $900^{\circ} \mathrm{C}$ to $-180^{\circ} \mathrm{C}$ called tetragonal $\left(\alpha-\mathrm{WO}_{3}\right)$, orthorhombic $\left(\beta-\mathrm{WO}_{3}\right)$, monoclinic I $\left(\gamma-\mathrm{WO}_{3}\right)$, triclinic $\left(\delta-\mathrm{WO}_{3}\right)$ and monoclinic II $\left(\varepsilon-\mathrm{WO}_{3}\right)[10]$. Due to the distortion of the original octahedra, $\mathrm{WO}_{3}$ band gap increases significantly. This means that the crystallographic arrangement determines the band gap of the semiconductor, increasing from $1.6 \mathrm{eV}$ to $2.4 \mathrm{eV}$ of the monoclinic structure [11]. Among all crystalline structures, the monoclinic structure is the most stable and the most efficient in PEC applications $[12,13]$. In addition to the crystal structure, the crystalline facet also has a great effect on the PEC processes where $\mathrm{WO}_{3}$ participates since the overpotential that is required for photooxidation on the surface of $\mathrm{WO}_{3}$ is totally conditioned on the orientation of the crystals [14]. Among all the crystalline facets, (002) is the most suitable for adsorption, redox reactions and degradations of organic pollutants [15]. It has been shown that the facet $(002)$ of $\mathrm{WO}_{3}$ facilitates the separation of photo-induced charges carrier and represses the formation of peroxo-species, producing a higher photocurrents and better photostability.

It has been reported that 2D nanostructures (nanoflake / nanoplate / nanosheet) have improved properties with respect to $1 \mathrm{D}$ nanostructures since they can orthogonalize the directions of the absorption of the incident light by the long axes and charge carriers can move through the short radius, causing greater efficiency in the absorption of light and 
in the collection of charge carriers, resulting in higher PEC efficiencies. In addition, the characteristic porous morphology allows photogenerated minority carriers to be accumulated in an orthogonal direction over short distances. With low minority carrier accumulation distances, high quantum yields (both external and internal) can be produced for accumulation of photogenerated charges [10].

Another important parameter to study is the temperature of the heat treatment that is given to the samples after their synthesis (annealing), since it has a great effect on the nanostructures converting their amorphous structure to a crystalline one. As the layers of $\mathrm{WO}_{3}$ contain a hydrated region, and therefore an amorphous structure, it must be transformed into a crystalline one to be used as electrochromic devices, in photoelectrochemical and photocatalytic processes, etc [16,17]. Heat treatment at high temperatures has been demonstrated to achieve that change, having a great influence on the morphology of the surface, on the crystal structure and on the phase transition $[18,19]$.

In a previous work [20], it was observed that high annealing temperatures $\left(600^{\circ} \mathrm{C}\right)$ enhanced the PEC performance of $\mathrm{WO}_{3}$ nanosheets/nanorods, increasing their efficiency as photoanodes for the degradation of persistent organic pollutants, such as the pesticide chlorfenvinphos. However, an exhaustive investigation about the influence of annealing conditions (temperature and atmosphere) on the PEC properties of $\mathrm{WO}_{3}$ nanostructures is required. It is therefore necessary to develop and implement extensive characterization procedures, especially from an electrochemical and photoelectrochemical point of view, to systematically study the influence of different parameters on the photoelectrochemical performance of new nanostructured photoanodes. This is the main objective and the novelty of the present work. To accomplish this objective, the structural, morphological and photoelectrochemical 
properties of $\mathrm{WO}_{3}$ nanostructures formed at various temperatures $\left(400^{\circ} \mathrm{C}, 500^{\circ} \mathrm{C}\right.$ and $600^{\circ} \mathrm{C}$ ) and under different atmosphere (air, $\mathrm{N}_{2}$ and Ar) were evaluated through Field Emission Scanning Electronic Microscopy (FESEM), Confocal Raman Spectroscopy, Photoelectrochemical Impedance Spectroscopy (PEIS) and Mott-Schottky analysis.

\section{EXPERIMENTAL PROCEDURE}

\subsection{Nanostructures fabrication}

$\mathrm{WO}_{3}$ nanostructures were fabricated by electrochemical anodization of tungsten cylinders ( $8 \mathrm{~mm}$ in diameter). Tungsten substrates were wet abraded with polishing paper grade 220, 1000 and 4000, rinsed with distilled water and dried with compressed air. Anodization was carried out in a $1.5 \mathrm{M} \mathrm{H}_{2} \mathrm{SO}_{4}+0.05 \mathrm{M} \mathrm{H}_{2} \mathrm{O}_{2}$ solution, using a platinum mesh as the cathode of the electrochemical cell and the tungsten samples as the anode. Electrolyte temperature was $50^{\circ} \mathrm{C}$ and the cell potential $20 \mathrm{~V}$. The tungsten electrode was continuously rotated at $375 \mathrm{rpm}$ by using a Rotating Disk Electrode (RDE). The circular area of the electrode exposed to the electrolyte was $0.5 \mathrm{~cm}^{-2}$. After $4 \mathrm{~h}$ of anodization, samples were annealed in a tubular oven using different temperatures $\left(400^{\circ} \mathrm{C}, 500^{\circ} \mathrm{C}\right.$ and $600^{\circ} \mathrm{C}$; higher temperatures were also used but nanostructures were collapsed) and different gaseous atmospheres (air, $\mathrm{N}_{2}$ and $\mathrm{Ar}$ ). 


\subsection{Morphological and structural characterization}

Field Emission Scanning Electronic Microscopy (FESEM) images were taken using a Zeiss Ultra 55 microscope, at $2 \mathrm{kV}$. Raman spectra were obtained with a confocal Raman microscope with a blue neon laser (488 nm).

\subsection{Photoelectrochemical characterization}

Photoelectrochemical characterization of the $\mathrm{WO}_{3}$ nanostructures was performed using a transparent quartz cell of $14 \mathrm{~mL}$ with a three-electrode configuration: a platinum tip counter electrode, an $\mathrm{Ag} / \mathrm{AgCl}(3 \mathrm{M} \mathrm{KCl})$ reference electrode and the nanostructures as the working electrodes. All tests were carried out in a $0.1 \mathrm{M} \mathrm{H}_{2} \mathrm{SO}_{4}$ electrolyte by using an Autolab PGSTAT302N potentiostat and under simulated sunlight (AM1.5 conditions) with a power intensity of $100 \mathrm{~mW} \mathrm{~cm}^{-2}$.

$\mathrm{WO}_{3}$ nanostructures were immersed in the photoelectrochemical cell without illumination and an external bias of $1 \mathrm{~V}$ was applied. After stabilizing dark current densities, samples were irradiated. Photocurrent densities were recorded for 30 minutes under these conditions. After that, Photoelectrochemical Impedance Spectroscopy tests (PEIS) were carried out from $10 \mathrm{kHz}$ to $10 \mathrm{mHz}$ and applying a potential perturbation of $10 \mathrm{mV}$. Subsequently, Mott-Schottky plots were constructed at $5 \mathrm{kHz}$ by scanning the potential from $1 \mathrm{~V}$ to $0.2 \mathrm{~V}$ at a rate of $50 \mathrm{mV} \mathrm{s}^{-1}$. 


\section{RESULTS AND DISCUSSION}

Figure 1 shows all the FESEM images for the different $\mathrm{WO}_{3}$ samples after annealing in different atmospheres (air, $\mathrm{N}_{2}$ and $\mathrm{Ar}$ ) at different temperatures $\left(400^{\circ} \mathrm{C}, 500^{\circ} \mathrm{C}\right.$ and $600^{\circ} \mathrm{C}$ ). Very small nanosheets or nanorods were formed in all the cases. Nevertheless, it can be observed that the morphology of these nanostructures became much more defined as annealing temperature increased. In fact, at $400^{\circ} \mathrm{C}$ and regardless of the annealing atmosphere, a nanosheet morphology with very small sizes was obtained, which was progressively transformed into nanorods at higher temperatures. At $600^{\circ} \mathrm{C}$ and for samples annealed in air and $\mathrm{N}_{2}$ atmospheres (Figure 1c and Figure 1f, respectively), a clear nanorod array morphology can be observed. According to Fan et al. [21], this kind of nanostructure offers efficient electron transfer from the $\mathrm{WO}_{3}$ to the back contact. The transformation from poorly defined nanosheets to clearly defined nanorods with increasing annealing temperature can be related to a higher degree of dehydration of the nanostructures, as explained in a previous work [20]. Other authors have also observed a change in $\mathrm{WO}_{3}$ nanostructures morphology with annealing temperature [21-26]. Concerning the influence of annealing atmosphere on the morphology and size of $\mathrm{WO}_{3}$ nanostructures, it can be observed that samples treated in air and $\mathrm{N}_{2}$ were similar, regardless of the temperature (Figures 1a-1c (air) and Figures 1g-1i (Ar)). The samples annealed in an Ar atmosphere at $400^{\circ} \mathrm{C}$ and $500^{\circ} \mathrm{C}$ (Figure $1 \mathrm{~g}$ and Figure 1h) were also similar to the ones annealed at the same temperature under air and $\mathrm{N}_{2}$. However, at $600^{\circ} \mathrm{C}$, the sample annealed in Ar was different, since nanorods were not observed. Instead, very small and deformed nanoplates or nanoparticles were obtained. This morphology might prevent photogenerated charges from being 
efficiently separated, hence reducing photoelectrochemical performance of nanostructures.

Figure 2 shows the Raman spectra of all the $\mathrm{WO}_{3}$ samples. The shape of all the spectra is similar, regardless of the annealing conditions. Characteristics peaks of crystalline $\mathrm{WO}_{3}$ are observed in the plots: $125 \mathrm{~cm}^{-1}, 195 \mathrm{~cm}^{-1}, 275 \mathrm{~cm}^{-1}, 715 \mathrm{~cm}^{-1}$ and $822 \mathrm{~cm}^{-1}$ [27-29]. However, there are some differences. At $400^{\circ} \mathrm{C}$, a very low-intensity band can be discerned at around $940-950 \mathrm{~cm}^{-1}$, as well as a shoulder at $\sim 650 \mathrm{~cm}^{-1}$, which has been associated habitually with amorphous hydrated $\mathrm{WO}_{3}\left(\mathrm{WO}_{3} \cdot \mathrm{xH}_{2} \mathrm{O}\right)$ [27-30]. These bands disappeared as annealing temperature increased in air and $\mathrm{N}_{2}$ atmospheres (Figure 2a and Figure 2b), indicating a higher degree of dehydration and crystallinity of nanostructures treated under those conditions. At $600^{\circ} \mathrm{C}$ for air and $\mathrm{N}_{2}$ atmospheres (Figure 2a and Figure 2b), the peak centered at $330 \mathrm{~cm}^{-1}$ became much clearer. This peak has also been related to crystalline $\mathrm{WO}_{3}$ [27-29], confirming a higher crystallinity of samples annealed at $600^{\circ} \mathrm{C}$ in air an $\mathrm{N}_{2}$ atmospheres. On the other hand, spectra of samples treated at $600^{\circ} \mathrm{C}$ in Ar atmosphere (Figure 2c) did not show the same tendency as samples annealing in the other atmospheres. Therefore, it can be said that this sample was less crystalline than the other samples annealed at the same temperature in other gaseous atmospheres.

The photoelectrocatalytic performance of the different nanostructures is shown in Figure 3. In this figure, the mean photocurrent density $\left(i_{p h}\right)$ obtained under simulated solar light, applying an external potential of $1 \mathrm{~V}_{\mathrm{Ag} / \mathrm{AgCl}}$ and after $30 \mathrm{~min}$ of stabilization, is represented for each temperature and annealing atmosphere. It can be seen that $i_{p h}$ 
values increased, in general, with increasing annealing temperature for all the atmospheres, except for the sample annealed in $\mathrm{Ar}$ at $600^{\circ} \mathrm{C}$. The enhancement of photoelectrocatalytic performance with annealing temperature can be explained by a better crystallinity [25,26,31-33], as observed in Raman spectra, as well as by the nanorod morphology obtained at high temperatures, which has been associated before with a better electronic transport through the $\mathrm{WO}_{3}$ nanostructure. In fact, the transition from poorly ordered nanosheets at $400^{\circ} \mathrm{C}$ to defined and ordered nanorods at $600^{\circ} \mathrm{C}$ can enhance electron and hole transfer within the nanostructure, hence increasing the photoelectrochemical performance of samples annealed at high temperatures [21]. According to Figure 3, the best photoelectrochemical performance corresponded to the nanostructure annealed at $600^{\circ} \mathrm{C}$ in an air atmosphere.

In order to study the mechanism of photocurrent generation in the $\mathrm{WO}_{3}$ nanostructures, and the influence of annealing conditions on the different electrochemical and photoelectrochemical phenomena taking place in the irradiated semiconducting nanostructures, Photoelectrochemical Impedance Spectroscopy (PEIS) experiments have been carried out. Figure 4 and Figure 5 show the Nyquist and Bode-phase plots under illumination for the different $\mathrm{WO}_{3}$ nanostructures, respectively. At first sight, only one semicircle was perceptible in the Nyquist plots. However, at high frequencies, a very small semicircle was also present (not shown). Besides, two peaks in Bode-phase plot for the sample annealed in air at $400^{\circ} \mathrm{C}$ could be clearly discerned, and a wide peak was evident in the rest of Bode plots, probably indicating the overlapping of two individual peaks. In Nyquist plots (Figure 4), the high-amplitude semicircle obtained at intermediate and low frequencies decreased, in general, with increasing annealing temperatures for all the atmospheres. When working with nanostructured semiconductor 
under illumination conditions, this semicircle has usually been associated in the literature with the charge transfer of holes from either the valence band or surface states to the electrolyte [34-38], where they can oxidize the media to form species such as gaseous oxygen, hydroxyl radicals, oxidized organic matter, etc. Therefore, the low frequency semicircle related to charge transfer of holes dominated the impedance response of all the samples. Hence, the decrease of impedance values with increasing annealing temperatures indicates a better photoelectrochemical response of the nanostructures treated at $600^{\circ} \mathrm{C}$ in air and $\mathrm{N}_{2}$ atmospheres. However, in Ar atmosphere, is spite of the semicircle being similar in amplitude for the samples annealed at $500^{\circ} \mathrm{C}$ and $600^{\circ} \mathrm{C}$, the photoelectrochemical response was lower at $600^{\circ} \mathrm{C}$, due to morphology differences (see Figure 1i). The previous results are consistent with the photocurrent density responses observed above (Figure 3). To quantitatively analyze impedance results, an electric equivalent circuit has been used (Figure 6). In this circuit, $R_{S}$ is the electrolyte resistance, the first $R_{1}-C P E_{1}$ time constant has been related to electron-hole trapping in surface states or in the bulk semiconductor, while the second $R_{2}-C P E_{2}$ time constant has been associated with hole transfer from $\mathrm{WO}_{3}$ to the electrolyte [35-38]. Constant Phase Elements $(C P E)$ have been used in this equivalent circuit to take into account the non-ideality of electrochemical capacitances.

Values of the resistances that make up the equivalent circuit are shown in Table $\mathbf{1}$ for all the samples. It can be observed that $R_{1}$ was always much lower than $R_{2}$, as expected. In general, $R_{2}$ decreased with increasing annealing temperature, indicating enhanced charge transfer of holes from the nanostructure to the electrolyte. A similar trend was observed by Zhu et al. [25]. In the case of the sample annealed at $600^{\circ} \mathrm{C}$ in an $\mathrm{Ar}$ atmosphere, it can be seen that the value of $R_{2}$ was higher than at $500^{\circ} \mathrm{C}$ in the same 
annealing atmosphere. This fact may be related to the morphology of nanostructures explained above, since at $600^{\circ} \mathrm{C}$ in Ar, deformed nanoplates were obtained (Figure 1i), which increased the charge transfer resistance of holes from the nanostructure to the electrolyte.

Impedance results can also be used to determine the density of dopants in a semiconductor, by means of the Mott-Schottky equation for an $n$-type semiconductor (such as $\mathrm{WO}_{3}$ ):

$$
\frac{1}{C^{2}}=\frac{1}{C_{H}^{2}}+\frac{2}{\varepsilon_{r} \varepsilon_{0} e N_{D}}\left(E-E_{F B}-\frac{k T}{e}\right)
$$

where $C$ is the measured total interfacial capacitance, $C_{H}$ is the capacitance of the Helmholtz layer, $\varepsilon_{r}$ is the dielectric constant of the semiconductor (50 for $\mathrm{WO}_{3}$ nanostructures $[23,39-41]), \varepsilon_{0}$ is the permittivity of free space $\left(8.85 \cdot 10^{-14} \mathrm{~F} / \mathrm{cm}\right), e$ is the elementary charge $\left(1.60 \cdot 10^{-19} \mathrm{C}\right), N_{D}$ is the density of donors in the semiconductor, $E$ is the applied potential, $E_{E F}$ is the flat-band potential, $k$ is the Boltzmann constant $\left(1.38 \cdot 10^{-23} \mathrm{~J} / \mathrm{K}\right)$ and $T$ is the absolute temperature.

According to equation (1), a plot of $1 / C^{2}$ vs $E$ should have a linear region with positive slope (for an $n$-type semiconductor), from which the value of $N_{D}$ can be obtained. MottSchottky plots are shown in Figure 7. In all cases, a linear region with positive slope can be observed (marked in the plots). This region is related to the presence of donor species within the crystalline structure of $\mathrm{WO}_{3}$, such as $\mathrm{W}^{6+}$ interstitials or oxygen 
vacancies. For samples annealed in $\mathrm{N}_{2}$ and Ar atmospheres, besides, another linear region with a much lower slope can be clearly observed at high potentials, especially for samples annealed at $400^{\circ} \mathrm{C}$. The presence of this linear region at high potentials in the Mott-Schottly plots can be attributed to near-surface deep-level electronic states which are potential dependant $[42,43]$ and that can therefore be charged or discharged, or to an unknown geometric factor [43]. The nature of these electronic states is not identified, although their relation with non-oxidizing atmospheres during annealing is evident.

All samples provided lower $1 / C^{2}$ values (higher capacitance values) and lower slopes when increasing annealing temperature, regardless of the used atmosphere. Results of density of donors are presented in Table 2. It can be seen that $N_{D}$ for samples annealed at $400^{\circ} \mathrm{C}$ and $500^{\circ} \mathrm{C}$ are similar, although slightly higher at $500^{\circ} \mathrm{C}$. However, at $600^{\circ}$ C, $N_{D}$ extensively increased for all samples, especially for the one annealed in the $\mathrm{N}_{2}$ atmosphere. In general, there is a correlation between high photocurrent densities, low charge transfer resistances $\left(R_{2}\right)$ and high donor densities $\left(N_{D}\right)$. It is reasonable, since a high density of donor species would result in higher mobility of electron and holes within the $\mathrm{WO}_{3}$ nanostructures, hence reducing charge transfer resistances and enhancing the photoelectrochemical performance of photoanodes.

The sample annealed at $600^{\circ} \mathrm{C}$ and in an air atmosphere has provided the highest photocurrent density values, showing an excellent photoelectrochemical behavior. This photoanode is, therefore, suitable to be used as high efficient photoelectrocatalysts in many environmental and energy applications. Consequently, besides presenting an extensive characterization procedure to investigate the properties of 
photoelectrocatalysts, the present work can contribute in an important way to the progress in photoelectrochemical technology applied to the environmental (degradation of recalcitrant organic pollutants, such as pesticides) and energy (generation of $\mathrm{H}_{2}$ through photoelectrochemical water splitting) fields.

\section{CONCLUSIONS}

- $\mathrm{WO}_{3}$ nanosheets were obtained annealing at $400^{\circ} \mathrm{C}$, while nanorods were obtained at higher annealing temperatures $\left(600^{\circ} \mathrm{C}\right)$. In the $\mathrm{Ar}$ atmosphere at $600^{\circ} \mathrm{C}$, nanostructures were deformed.

- As temperature increased from $400^{\circ} \mathrm{C}$ to $600^{\circ} \mathrm{C}$, samples became completely crystalline and dehydrated.

- The best photoelectrochemical performance was obtained for the sample treated at $600^{\circ} \mathrm{C}$ in air. For samples annealed in Ar, photocurrent densities decreased at $600^{\circ}$ C due to the poorly defined nanostructures.

- Hole transfer resistance decreased in general with increasing annealing temperatures, indicating enhanced charge transfer of holes and, consequently, improved photoelectrocatalytic properties.

- The density of dopant species (donor) increased with increasing annealing temperature. Therefore, there is a direct correlation between high photocurrent densities, low hole transfer resistances and high donor densities. 


\section{Aknowledgements}

Authors thank for the financial support to the Ministerio de Economía y Competitividad (Project Codes: CTQ2016-79203-R and CTQ2017-90659-REDT (MEIS/AEI)), for its help in the Laser Raman Microscope acquisition (UPOV08-3E-012) and for the cofinance by the European Social Fund. Ramón M. Fernández Domene also thanks the UPV for the concession of a post-doctoral grant (PAID-10-17) and Gemma Roselló Márquez also thanks the Generalitat Valenciana for the concession of a pre-doctoral grant (ACIF/2018/159).

\section{REFERENCES}

[1] Y.M. Hunge, V.S. Mohite, S.S. Kumbhar, K.Y. Rajpure, A. V. Moholkar, C.H. Bhosale, Photoelectrocatalytic degradation of methyl red using sprayed $\mathrm{WO}_{3}$ thin films under visible light irradiation, J. Mater. Sci. Mater. Electron. 26 (2015) 8404-8412. doi:10.1007/s10854-015-3508-z.

[2] Y.M. Hunge, A.A. Yadav, M.A. Mahadik, V.L. Mathe, C.H. Bhosale, A highly efficient visible-light responsive sprayed $\mathrm{WO}_{3} / \mathrm{FTO}$ photoanode for photoelectrocatalytic degradation of brilliant blue, J. Taiwan Inst. Chem. Eng. 85 (2018) 273-281. doi:10.1016/j.jtice.2018.01.048.

[3] M. Rakibuddin, H. Kim, Synthesis and characterization of facile industrially scalable and cost effective $\mathrm{WO}_{3}$ micro-nanostructures for electrochromic devices and photocatalyst, Ceram. Int. 44 (2018) 16615-16623. doi:10.1016/j.ceramint.2018.06.088. 
[4] A.F. Palmstrom, P.K. Santra, S.F. Bent, Atomic layer deposition in nanostructured photovoltaics: tuning optical, electronic and surface properties, Nanoscale. 7 (2015) 12266-12283. doi:10.1039/c5nr02080h.

[5] C. Di Valentin, G. Pacchioni, Spectroscopic properties of doped and defective semiconducting oxides from hybrid density functional calculations, Acc. Chem. Res. 47 (2014) 3233-3241. doi:10.1021/ar4002944.

[6] J. Zhang, X. Chang, C. Li, A. Li, S. Liu, T. Wang, J. Gong, $\mathrm{WO}_{3}$ photoanodes with controllable bulk and surface oxygen vacancies for photoelectrochemical water oxidation, J. Mater. Chem. A. 6 (2018) 3350-3354. doi:10.1039/c7ta10056f.

[7] Z.F. Huang, J. Song, L. Pan, X. Zhang, L. Wang, J.J. Zou, Tungsten oxides for photocatalysis, electrochemistry, and phototherapy, Adv. Mater. 27 (2015) 53095327. doi:10.1002/adma.201501217.

[8] Y.M. Hunge, M.A. Mahadik, S.S. Kumbhar, V.S. Mohite, K.Y. Rajpure, N.G. Deshpande, A. V. Moholkar, C.H. Bhosale, Visible light catalysis of methyl orange using nanostructured $\mathrm{WO}_{3}$ thin films, Ceram. Int. 42 (2016) 789-798. doi:10.1016/j.ceramint.2015.08.178.

[9] J. Zhu, W. Li, J. Li, Y. Li, H. Hu, Y. Yang, Photoelectrochemical activity of $\mathrm{NiWO}_{4} / \mathrm{WO}_{3}$ heterojunction photoanode under visible light irradiation, Electrochim. Acta. 112 (2013) 191-198. doi:10.1016/j.electacta.2013.08.146.

[10] S.S. Kalanur, L.T. Duy, H. Seo, Recent Progress in Photoelectrochemical Water Splitting Activity of $\mathrm{WO}_{3}$ Photoanodes, Springer US, 2018. doi:10.1007/s11244- 
018-0950-1.

[11] D.W. Bullet, Bulk and surface electron states in $\mathrm{WO}_{3}$ and tungsten bronzes, J. Phys. C: Solid State Phys., 16 (1983) 2197-2207.

[12] S.S. Kalanur, Y.J. Hwang, S.Y. Chae, O.S. Joo, Facile growth of aligned $\mathrm{WO}_{3}$ nanorods on FTO substrate for enhanced photoanodic water oxidation activity, J. Mater. Chem. A 1 (2013) 3479-3488. doi:10.1039/c3ta01175e.

[13] D.B. Migas, V. L. Shaposhnikov, V. N. Rodin, V. E. Borisenko, Tungsten oxides. I. Effects of oxygen vacancies and doping on electronic and optical properties of different phases of $\mathrm{WO}_{3}$, J. Appl. Phys. 108 (2010) 093713. doi:10.1063/1.3505688.

[14] Á. Valdés, G.-J. Kroes, First principles study of the photo-oxidation of water on tungsten trioxide $\left(\mathrm{WO}_{3}\right), \quad$ J. Appl. Phys. $130 \quad$ (2009) 114701. doi:10.1063/1.3088845.

[15] Y. Guo, X. Quan, N. Lu, H. Zhao, S. Chen, High Photocatalytic Capability of Self-Assembled Nanoporous $\mathrm{WO}_{3}$ with Preferential Orientation of (002) Planes, Environ. Sci. Technol. 41 (2007) 4422-4427.

[16] Y. Liu, Y. Li, W. Li, S. Han, C. Liu, Applied Surface Science Photoelectrochemical properties and photocatalytic activity of nitrogen-doped nanoporous $\mathrm{WO}_{3}$ photoelectrodes under visible light, 258 (2012) 5038-5045. doi:10.1016/j.apsusc.2012.01.080.

[17] C. Ng, Y.H. Ng, A. Iwase, R. Amal, Influence of Annealing Temperature of $\mathrm{WO}_{3}$ in Photoelectrochemical Conversion and Energy Storage for Water Splitting, ACS Appl. Mater. Interfaces 5 (2013) 5269-5275. doi: 10.1021/am401112q 
[18] S.J. Hong, H. Jun, P.H. Borse, J.S. Lee, Size effects of $\mathrm{WO}_{3}$ nanocrystals for photooxidation of water in particulate suspension and photoelectrochemical film systems, Int. J. Hydrogen Energy. $34 \quad$ (2009) 3234-3242. doi:10.1016/j.ijhydene.2009.02.006.

[19] T. Zhu, M. Nan, Y. Wen, E. Chan, Colloids and Surfaces A : Physicochemical and Engineering Aspects Electrochemically synthesized tungsten trioxide nanostructures for photoelectrochemical water splitting: Influence of heat treatment on physicochemical properties, photocurrent densities, Colloids Surfaces A Physicochem. Eng. Asp. $484 \quad$ (2015) 297-303. doi:10.1016/j.colsurfa.2015.08.016.

[20] R.M. Fernández-Domene, G. Roselló-Márquez, R. Sánchez-Tovar, B. LucasGranados, J. García-Antón, Photoelectrochemical removal of chlorfenvinphos by using $\mathrm{WO}_{3}$ nanorods: Influence of annealing temperature and operation $\mathrm{pH}$, Sep. Purif. Technol. 212 (2019) 458-464. doi:10.1016/j.seppur.2018.11.049.

[21] X. Fan, B. Gao, T. Wang, X. Huang, H. Gong, H. Xue, H. Guo, L. Song, W. Xia, J. He, Layered double hydroxide modified $\mathrm{WO}_{3}$ nanorod arrays for enhanced photoelectrochemical water splitting, Appl. Catal. A Gen. 528 (2016) 52-58. doi:10.1016/j.apcata.2016.09.014.

[22] S.J. Hong, H. Jun, P.H. Borse, J.S. Lee, Size effects of $\mathrm{WO}_{3}$ nanocrystals for photooxidation of water in particulate suspension and photoelectrochemical film systems, Int. J. Hydrogen Energy. $34 \quad$ (2009) 3234-3242. doi:10.1016/j.ijhydene.2009.02.006. 
[23] Y. Liu, Y. Li, W. Li, S. Han, C. Liu, Photoelectrochemical properties and photocatalytic activity of nitrogen-doped nanoporous $\mathrm{WO}_{3}$ photoelectrodes under visible light, Appl. Surf. Sci. $258 \quad$ (2012) 5038-5045. doi:10.1016/j.apsusc.2012.01.080.

[24] C. Ng, Y.H. Ng, A. Iwase, R. Amal, Influence of annealing temperature of $\mathrm{WO}_{3}$ in photoelectrochemical conversion and energy storage for water splitting, ACS Appl. Mater. Interfaces. 5 (2013) 5269-5275. doi:10.1021/am401112q.

[25] T. Zhu, M.N. Chong, Y.W. Phuan, E.S. Chan, Electrochemically synthesized tungsten trioxide nanostructures for photoelectrochemical water splitting: Influence of heat treatment on physicochemical properties, photocurrent densities and electron shuttling, Colloids Surfaces A Physicochem. Eng. Asp. 484 (2015) 297-303. doi:10.1016/j.colsurfa.2015.08.016.

[26] Y. Chai, C.W. Tam, K.P. Beh, F.K. Yam, Z. Hassan, Effects of thermal treatment on the anodic growth of tungsten oxide films, Thin Solid Films. 588 (2015) 4449. doi:10.1016/j.tsf.2015.04.033.

[27] M.F. Daniel, B. Desbat, J.C. Lassegues, B. Gerand, M. Figlarz, Infrared and Raman study of $\mathrm{WO}_{3}$ tungsten trioxides and $\mathrm{WO}_{3}, \mathrm{xH}_{2} \mathrm{O}$ tungsten trioxide tydrates, J. Solid State Chem. 67 (1987) 235-247. doi:10.1016/00224596(87)90359-8.

[28] C. Bittencourt, R. Landers, E. Llobet, X. Correig, J. Calderer, The role of oxygen partial pressure and annealing temperature on the formation of $\mathrm{W}=\mathrm{O}$ bonds in thin $\mathrm{WO}_{3}$ films, Semicond. Sci. Technol. 17 (2002) 522-525. doi:10.1088/0268- 
$1242 / 17 / 6 / 304$.

[29] C.K. Wang, C.K. Lin, C.L. Wu, S.C. Wang, J.L. Huang, Synthesis and characterization of electrochromic plate-like tungsten oxide films by acidic treatment of electrochemical anodized tungsten, Electrochim. Acta. 112 (2013) 24-31. doi:10.1016/j.electacta.2013.07.204.

[30] S.H. Lee, H.M. Cheong, C.E. Tracy, A. Mascarenhas, D.K. Benson, S.K. Deb, Raman spectroscopic studies of electrochromic a- $\mathrm{WO}_{3}$, Electrochim. Acta. 44 (1999) 3111-3115. doi:10.1016/S0013-4686(99)00027-4.

[31] K.S. Ahn, S.H. Lee, A.C. Dillon, C.E. Tracy, R. Pitts, The effect of thermal annealing on photoelectrochemical responses of $\mathrm{WO}_{3}$ thin films, J. Appl. Phys. 101 (2007) 1-5. doi:10.1063/1.2729472.

[32] Y.W. Phuan, M.N. Chong, T. Zhu, S.T. Yong, E.S. Chan, Effects of annealing temperature on the physicochemical, optical and photoelectrochemical properties of nanostructured hematite thin films prepared via electrodeposition method, Mater. Res. Bull. 69 (2015) 71-77. doi:10.1016/j.materresbull.2014.12.059.

[33] Q. Zeng, J. Li, J. Bai, X. Li, L. Xia, B. Zhou, Preparation of vertically aligned $\mathrm{WO}_{3}$ nanoplate array films based on peroxotungstate reduction reaction and their excellent photoelectrocatalytic performance, Appl. Catal. B Environ. 202 (2017) 388-396. doi:10.1016/j.apcatb.2016.09.045.

[34] W.H. Leng, Z. Zhang, J.Q. Zhang, C.N. Cao, Investigation of the kinetics of a $\mathrm{TiO}_{2}$ photoelectrocatalytic reaction involving charge transfer and recombination through surface states by electrochemical impedance spectroscopy, J. Phys. Chem. B. 109 (2005) 15008-15023. doi:10.1021/jp051821z. 
[35] B. Klahr, S. Gimenez, F. Fabregat-Santiago, T. Hamann, J. Bisquert, Water oxidation at hematite photoelectrodes: The role of surface states, J. Am. Chem. Soc. 134 (2012) 4294-4302. doi:10.1021/ja210755h.

[36] L. Bertoluzzi, J. Bisquert, Equivalent circuit of electrons and holes in thin semiconductor films for photoelectrochemical water splitting applications, J. Phys. Chem. Lett. 3 (2012) 2517-2522. doi:10.1021/jz3010909.

[37] L. Bertoluzzi, P. Lopez-Varo, J.A. Jiménez Tejada, J. Bisquert, Charge transfer processes at the semiconductor/electrolyte interface for solar fuel production: Insight from impedance spectroscopy, J. Mater. Chem. A. 4 (2016) 2873-2879. doi:10.1039/c5ta03210e.

[38] V. Cristino, S. Marinello, A. Molinari, S. Caramori, S. Carli, R. Boaretto, R. Argazzi, L. Meda, C.A. Bignozzi, Some aspects of the charge transfer dynamics in nanostructured $\mathrm{WO}_{3}$ films, J. Mater. Chem. A. 4 (2016) 2995-3006. doi:10.1039/c5ta06887h.

[39] M. Yagi, S. Maruyama, K. Sone, K. Nagai, T. Norimatsu, Preparation and photoelectrocatalytic activity of a nano-structured $\mathrm{WO}_{3}$ platelet film, J. Solid State Chem. 181 (2008) 175-182. doi:10.1016/j.jssc.2007.11.018.

[40] W. Li, J. Li, X. Wang, J. Ma, Q. Chen, Photoelectrochemical and physical properties of $\mathrm{WO}_{3}$ films obtained by the polymeric precursor method, Int. J. Hydrogen Energy. 35 (2010) 13137-13145. doi:10.1016/j.ijhydene.2010.09.011. 
[41] F. Amano, M. Tian, B. Ohtani, A. Chen, Photoelectrochemical properties of tungsten trioxide thin film electrodes prepared from facet-controlled rectangular platelets, J. Solid State Electrochem. 16 (2012) 1965-1973. doi:10.1007/s10008011-1586-2.

[42] D.. Bonham, M.E. Orazem, A Mathematical Model for the Influence of DeepLevel Electronic States on Photoelectrochemical Impedance Spectroscopy. I. Theoretical Development, J. Electrochem. Soc. 139 (1992) 118-126. doi:10.1149/1.2069155.

[43] K. Siuzdak, M. Szkoda, M. Sawczak, A. Lisowska-Oleksiak, J. Karczewski, J. Ryl, Enhanced photoelectrochemical and photocatalytic performance of iodinedoped titania nanotube arrays, RSC Adv. 5 (2015) 50379-50391. doi:10.1039/c5ra08407e. 


\section{Tables and Figures captions}

Table 1. Resistance values of the the $\mathrm{WO}_{3}$ nanostructures annealed at different temperatures and in different atmospheres.

Table 2. Density of donors, $N_{D}$, of the the $\mathrm{WO}_{3}$ nanostructures annealed at different temperatures and in different atmospheres.

Figure 1. FESEM images of the $\mathrm{WO}_{3}$ nanostructures annealed in an air atmosphere at a) $400^{\circ} \mathrm{C}$, b) $500^{\circ} \mathrm{C}$ and c) $600^{\circ} \mathrm{C}$; in a $\mathrm{N}_{2}$ atmosphere at d) $400^{\circ} \mathrm{C}$, e) $500^{\circ} \mathrm{C}$ and f) $600^{\circ} \mathrm{C}$; in an Ar atmosphere at g) $400^{\circ} \mathrm{C}$; h) $500^{\circ} \mathrm{C}$ and i) $600^{\circ} \mathrm{C}$.

Figure 2. Raman spectra of $\mathrm{WO}_{3}$ nanostructures annealed at different temperatures in a) air; b) $\mathrm{N}_{2}$ and c) Ar.

Figure 3. Mean values of photocurrent density for the $\mathrm{WO}_{3}$ nanostructures annealed at different temperatures and in different atmospheres, obtained under simulated solar light applying an external potential of $1 \mathrm{~V}_{\mathrm{Ag} / \mathrm{AgCl}}$ and after $30 \mathrm{~min}$ of stabilization

Figure 4. Nyquist plots under simulated solar light $\mathrm{AM} 1.5$ for the $\mathrm{WO}_{3}$ nanostructures annealed at different temperatures in a) air; b) $\mathrm{N}_{2}$ and c) Ar.

Figure 5. Bode-phase plots under simulated solar light AM1.5 for the $\mathrm{WO}_{3}$ nanostructures annealed at different temperatures in a) air; b) $\mathrm{N}_{2}$ and c) Ar.

Figure 6. Electric equivalent circuit used to analyze EIS data.

Figure 7. Mott-Schottky plots under simulated solar light AM1.5 for the $\mathrm{WO}_{3}$ nanostructures annealed at different temperatures in a) air; b) $\mathrm{N}_{2}$ and c) Ar. 
Figure 1

(a)
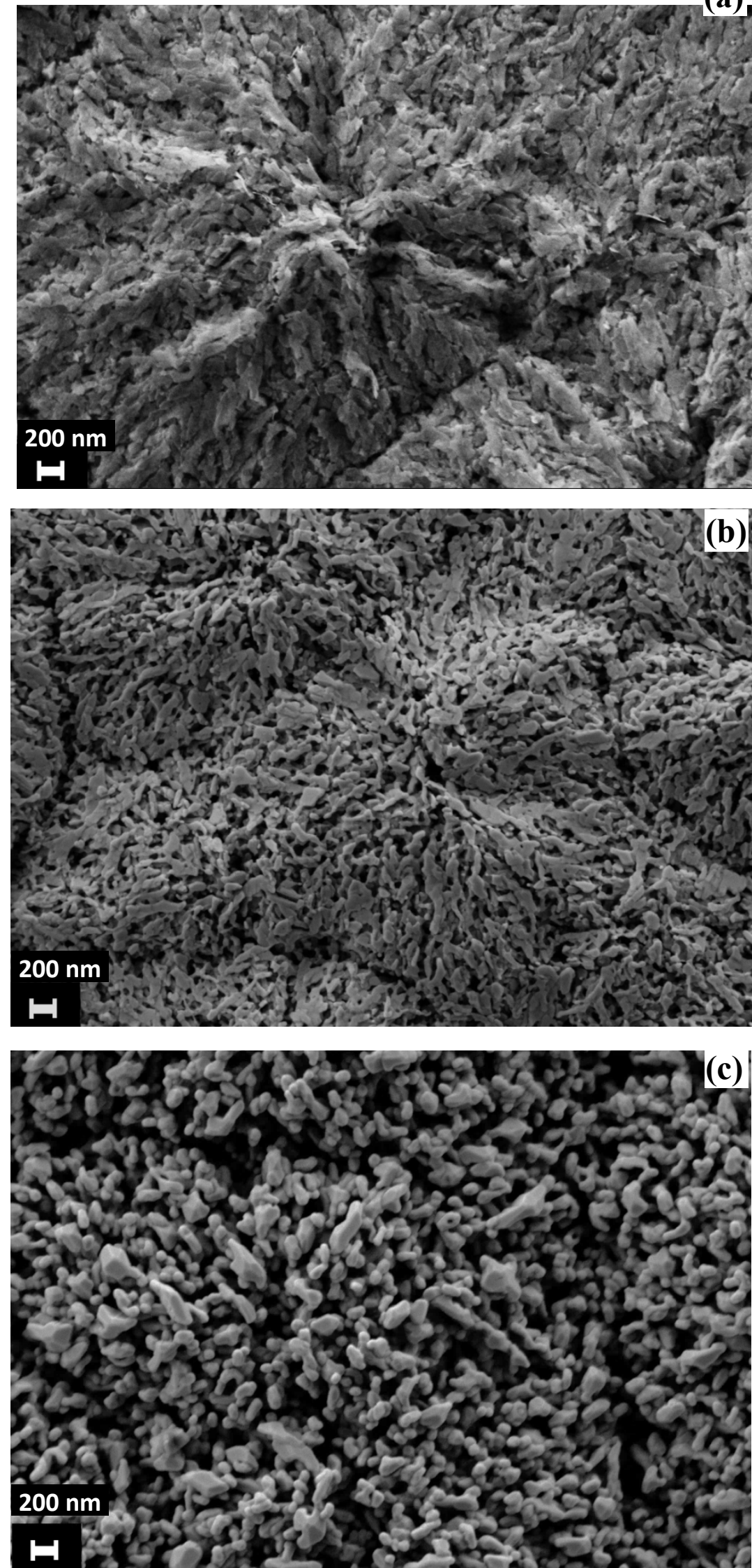

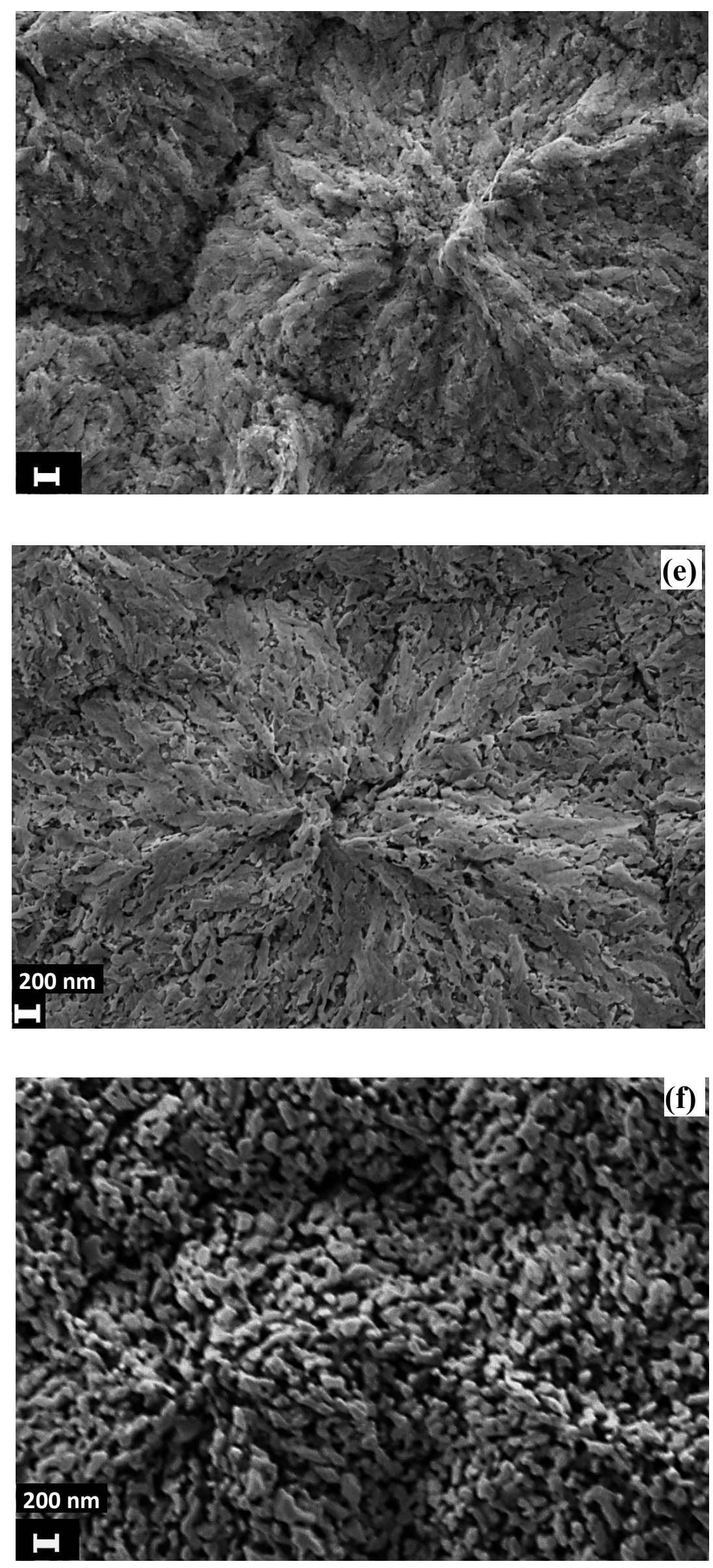

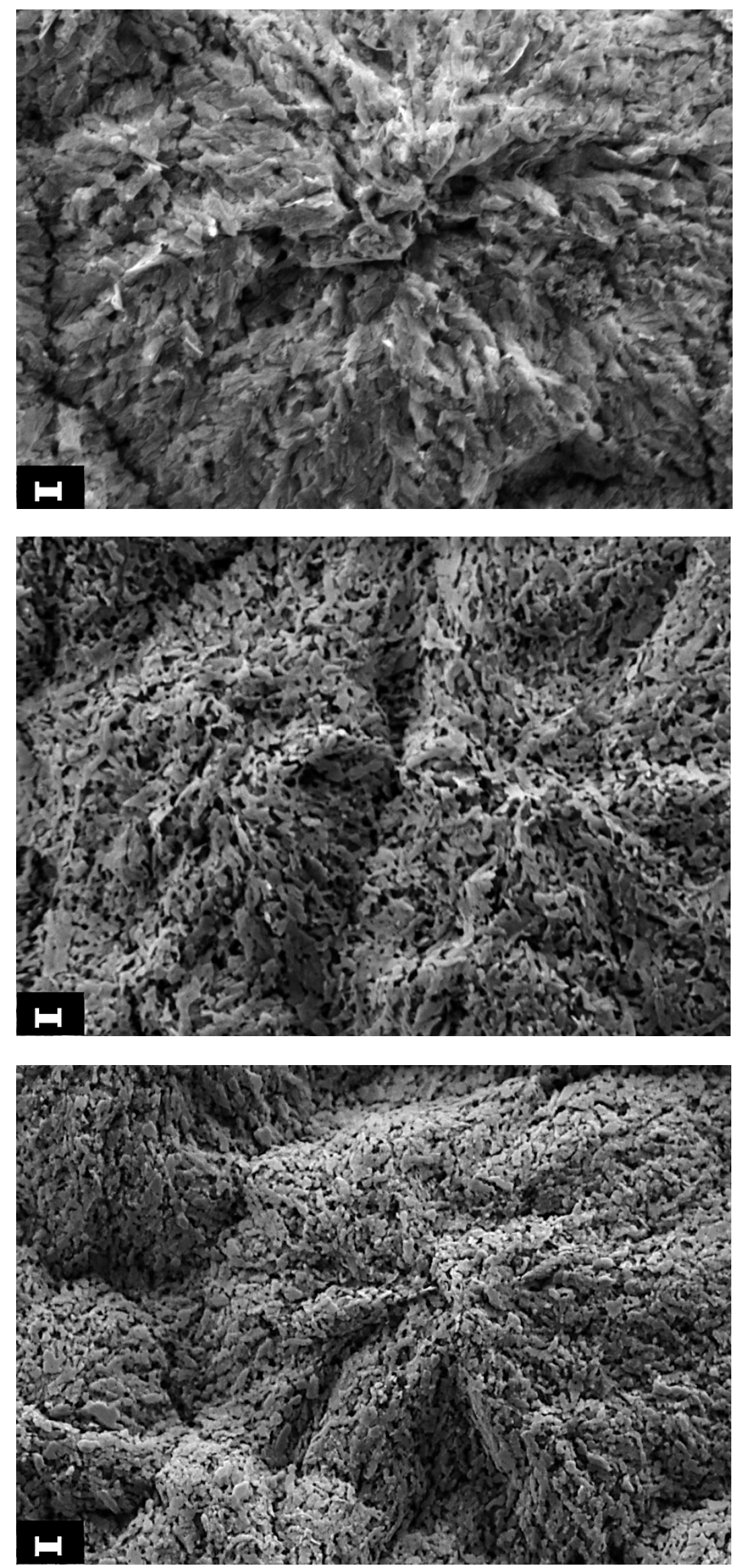
Figure 2

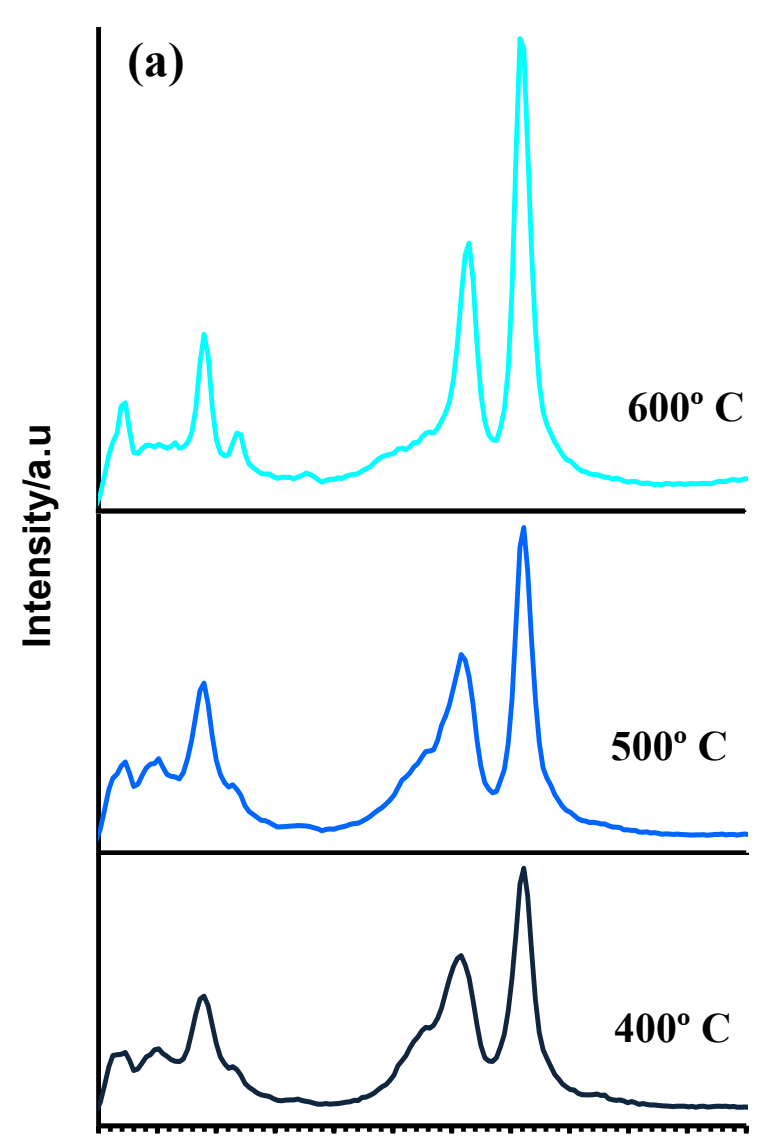

$00 \quad 200 \quad 300 \quad 400 \quad 500 \quad 600700800900 \quad 100011001200$ Raman shift $/ \mathrm{cm}^{-1}$
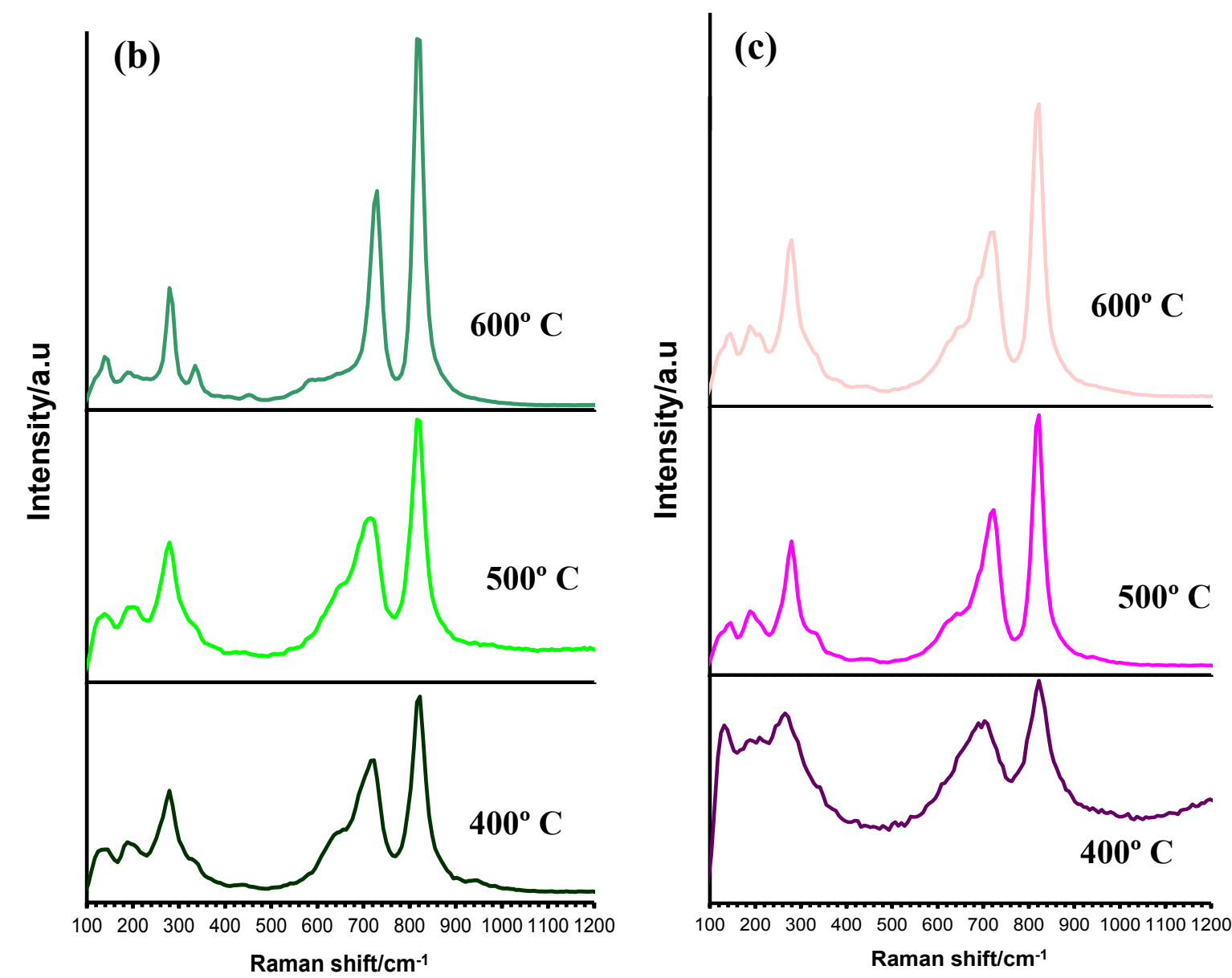
Figure 3

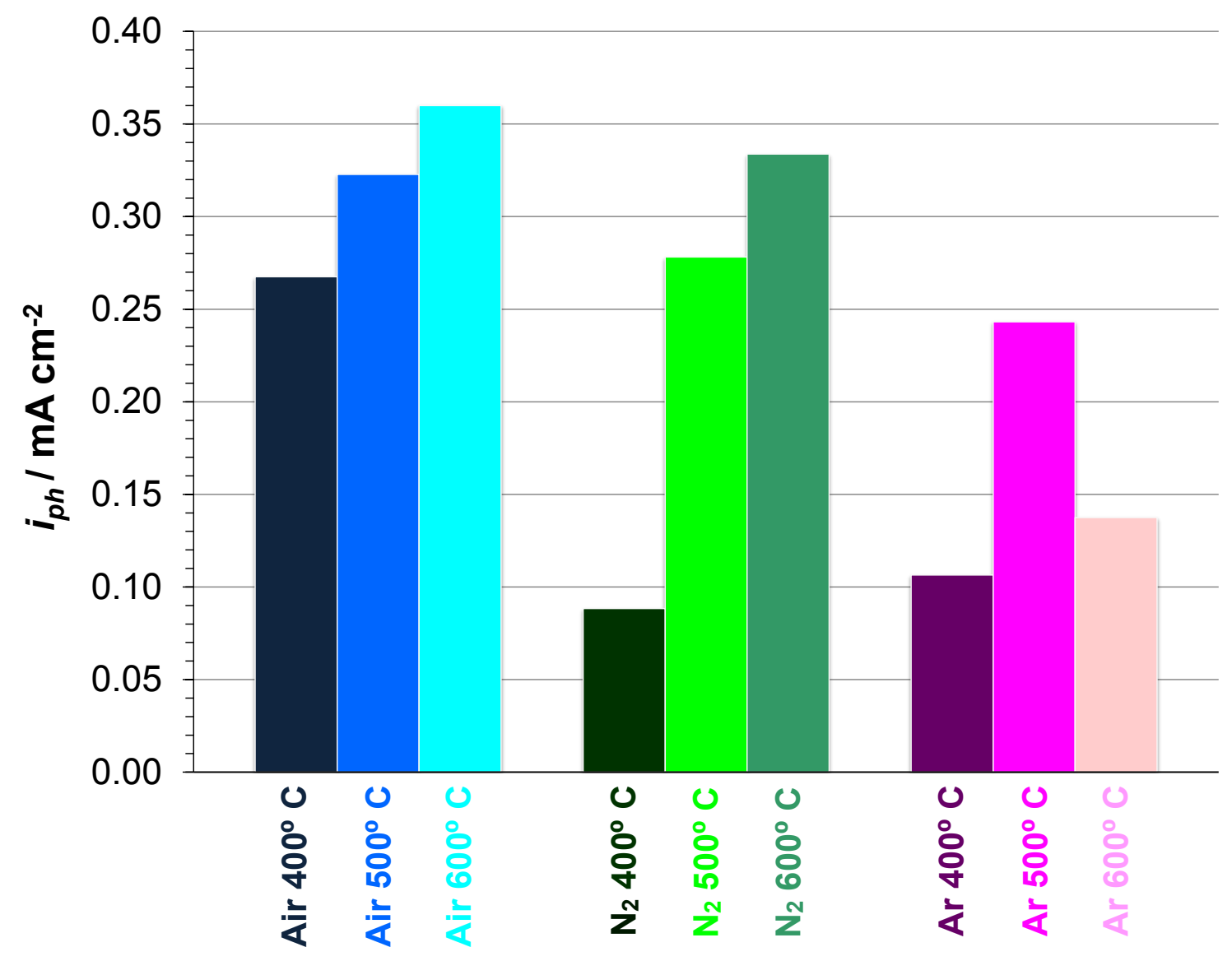


Figure 4
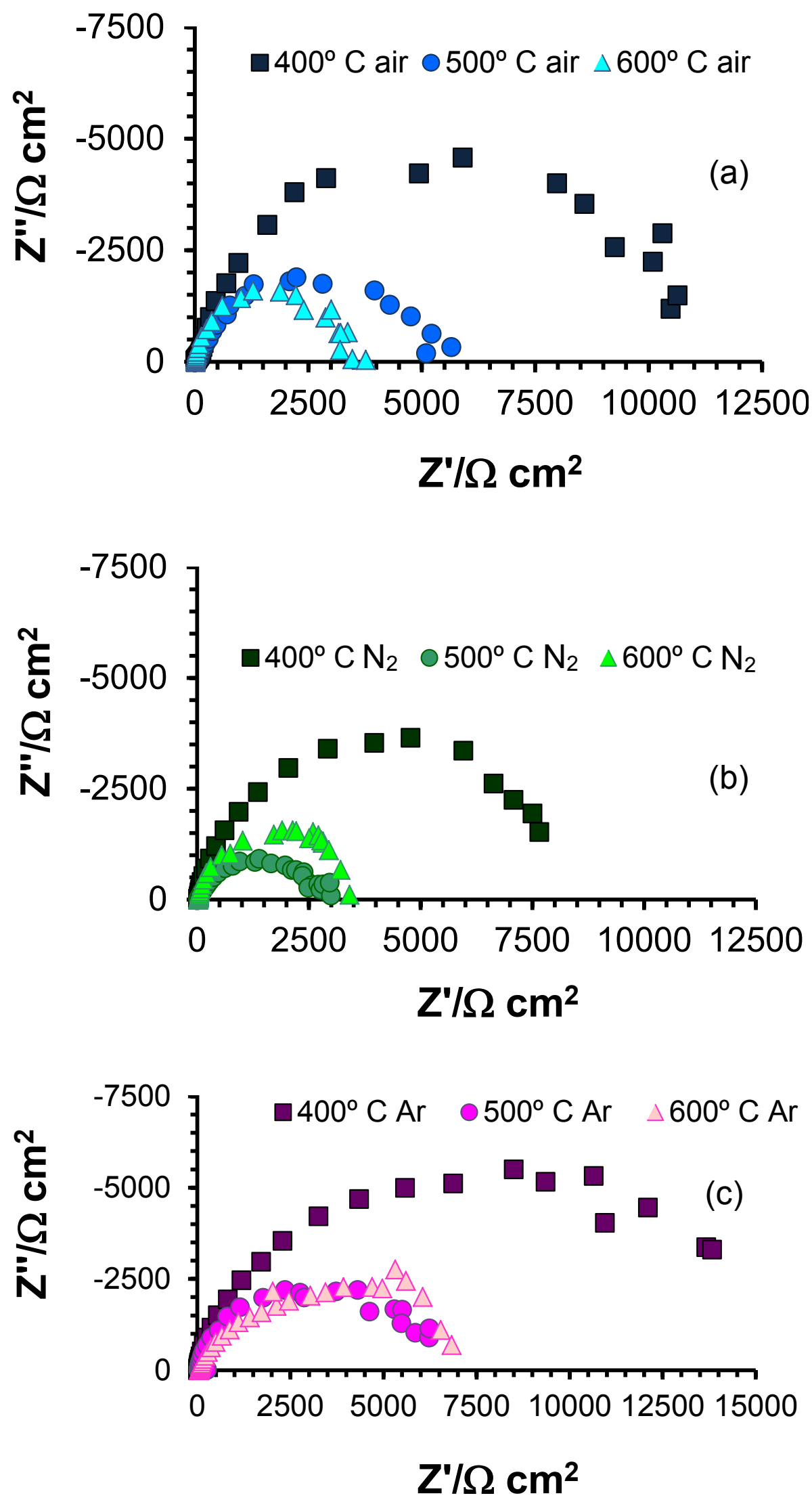
Figure 5

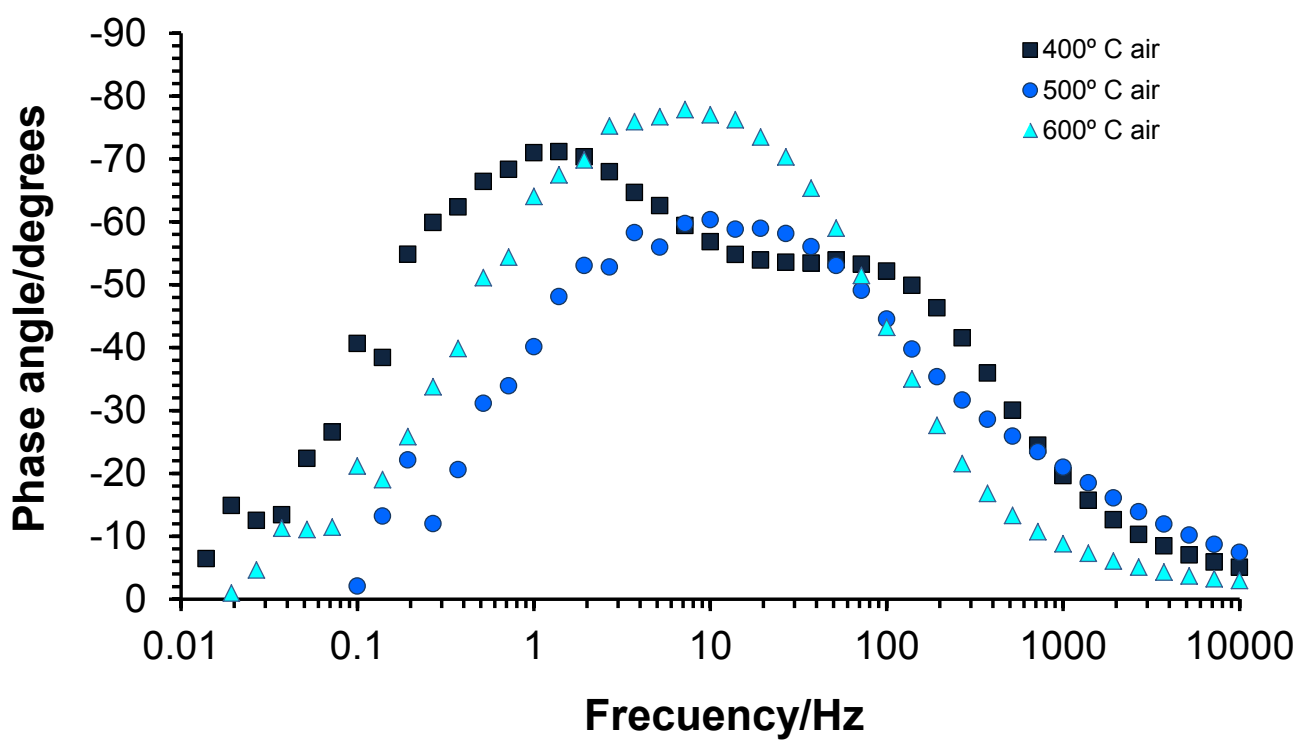

(a)

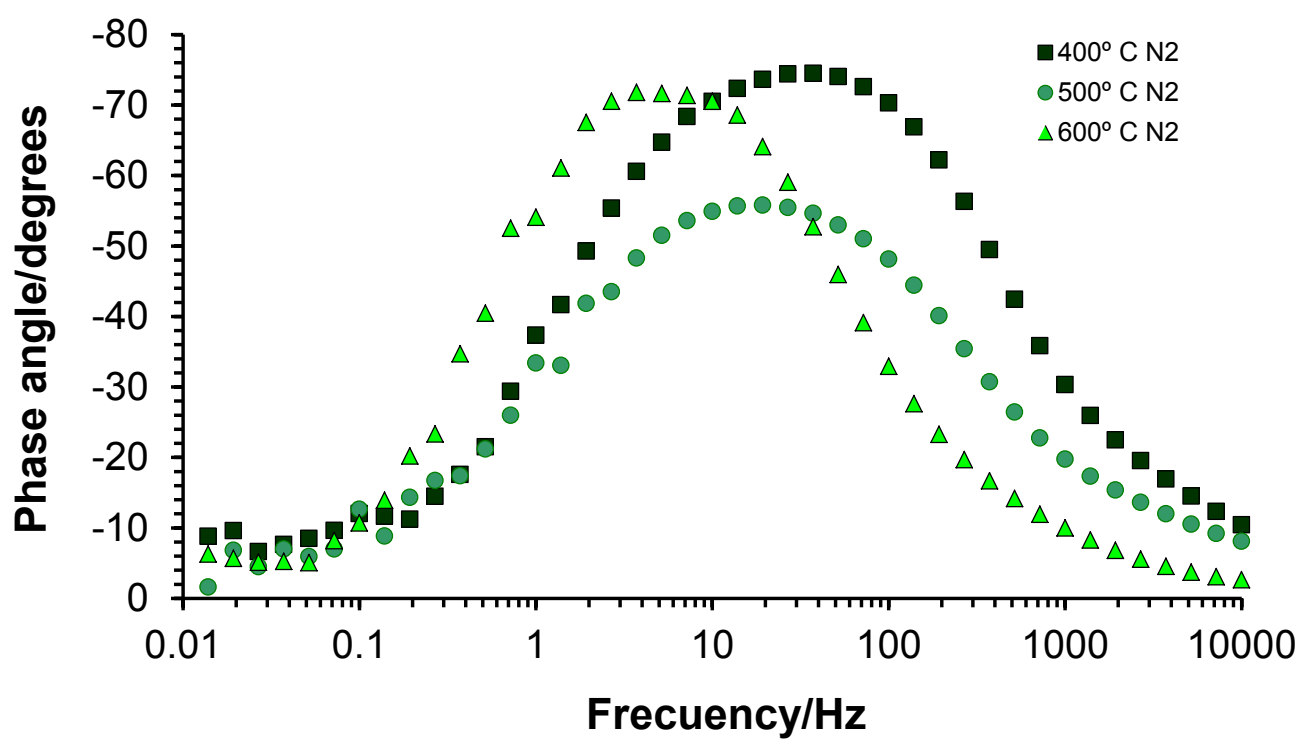

(b) 


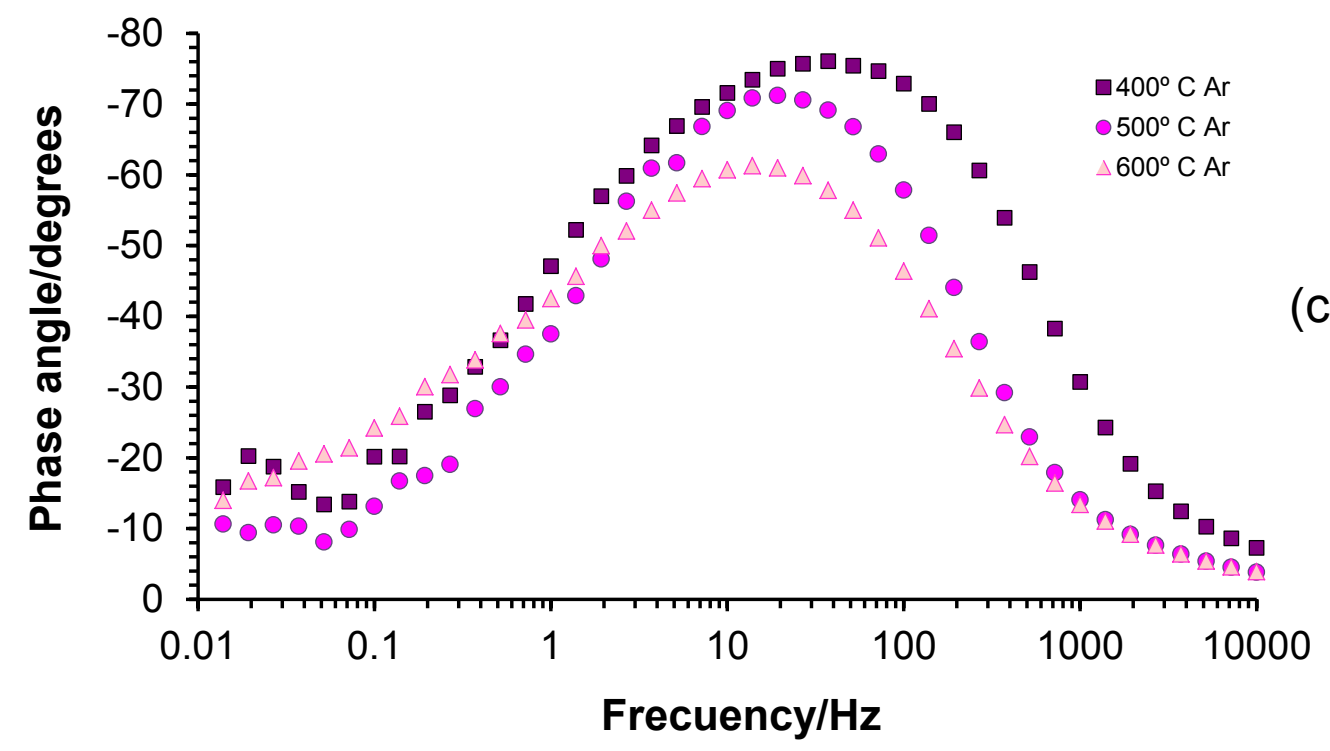

(c)

Figure 6

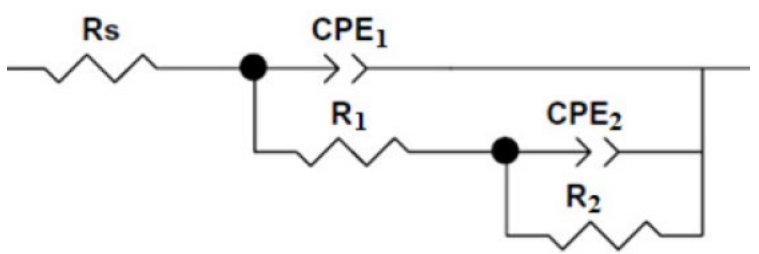


Figure 7
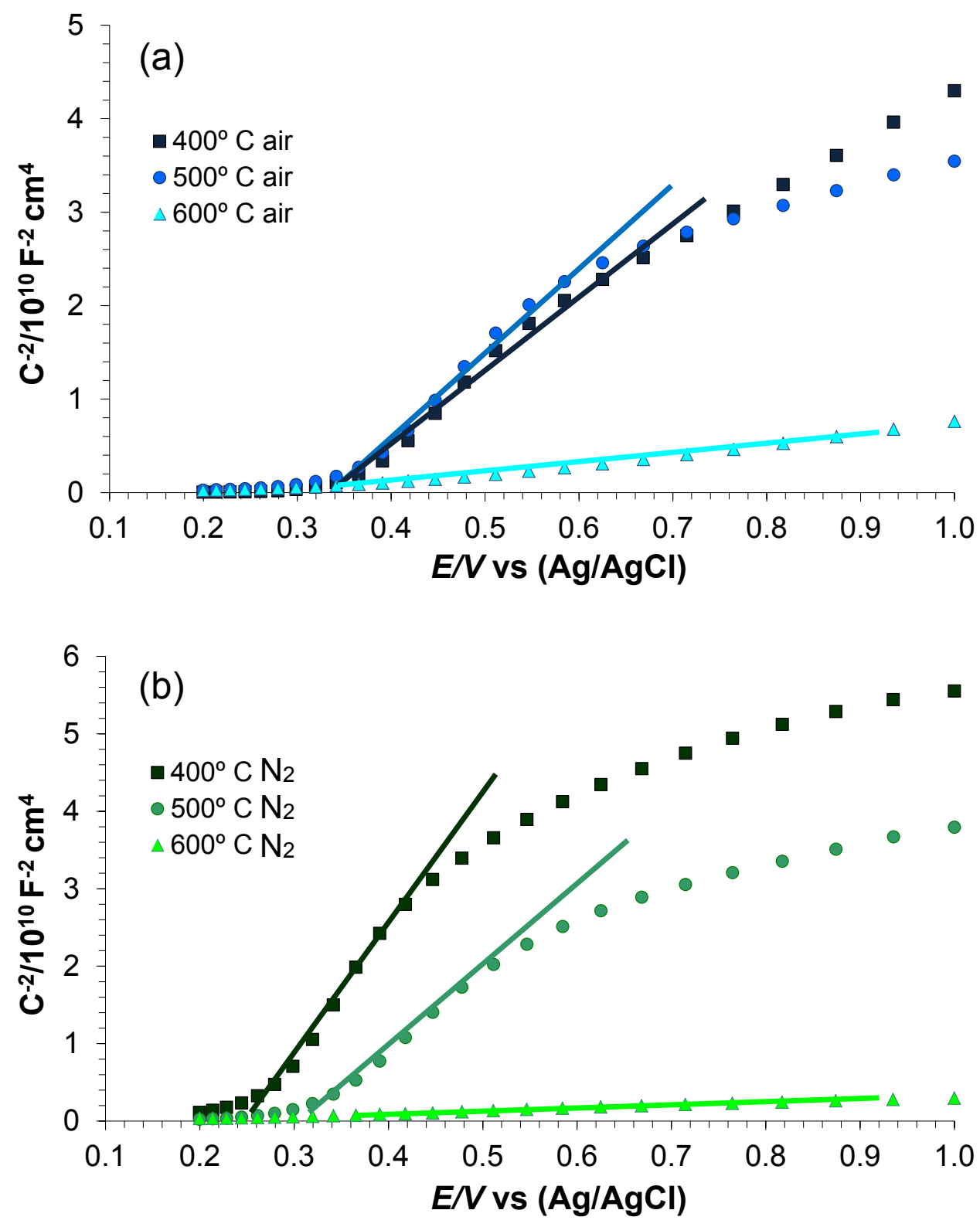


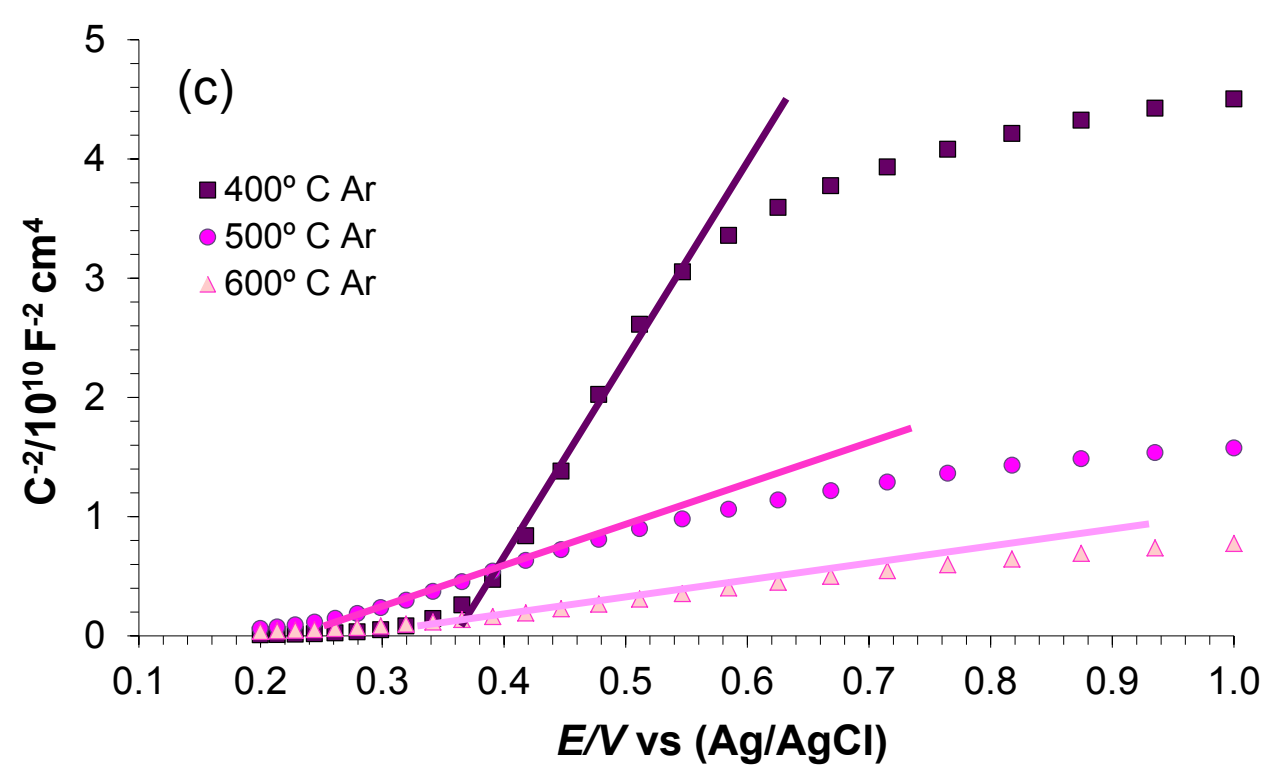

Table 1

\begin{tabular}{|c|c|c|c|c|}
\hline Atmosphere & $\boldsymbol{T} /{ }^{\circ} \boldsymbol{C}$ & $\boldsymbol{R}_{\boldsymbol{S}} / \mathbf{\Omega} \mathbf{~ c m}^{\mathbf{2}}$ & $\boldsymbol{R}_{1} / \mathbf{\Omega} \mathbf{~ c m}^{\mathbf{2}}$ & $\boldsymbol{R}_{2} / \mathbf{k} \boldsymbol{\Omega} \mathbf{~ m}^{\mathbf{2}}$ \\
\hline \multirow{3}{*}{ Air } & 400 & $29 \pm 3$ & $159 \pm 11$ & $11.8 \pm 1.6$ \\
\cline { 2 - 5 } & 500 & $44 \pm 9$ & $107 \pm 26$ & $7.6 \pm 1.3$ \\
\cline { 2 - 5 } & 600 & $28 \pm 6$ & $26 \pm 7$ & $3.0 \pm 0.9$ \\
\hline \multirow{3}{*}{$\mathrm{N}_{2}$} & 400 & $27 \pm 6$ & $5 \pm 1$ & $10.1 \pm 4.0$ \\
\cline { 2 - 5 } & 500 & $32 \pm 2$ & $31 \pm 5$ & $2.7 \pm 0.3$ \\
\cline { 2 - 5 } & 600 & $27 \pm 3$ & $22 \pm 9$ & $2.9 \pm 0.4$ \\
\hline \multirow{3}{*}{ Ar } & 400 & $37 \pm 8$ & $16 \pm 2$ & $14.9 \pm 0.8$ \\
\cline { 2 - 5 } & 500 & $27 \pm 1$ & $32 \pm 9$ & $7.4 \pm 0.1$ \\
\cline { 2 - 5 } & 600 & $22 \pm 4$ & $21 \pm 3$ & $9.6 \pm 3.7$ \\
\hline
\end{tabular}


Table 2

\begin{tabular}{|c|c|c|}
\hline Atmosphere & T/o $C$ & $N_{D}\left(\times \mathbf{1 0}^{19} \mathbf{c m}^{-3}\right)$ \\
\hline \multirow{3}{*}{ Air } & 400 & $2.6 \pm 0.3$ \\
\cline { 2 - 3 } & 500 & $2.9 \pm 0.5$ \\
\cline { 2 - 3 } & 600 & $20.4 \pm 8.6$ \\
\hline \multirow{3}{*}{$\mathrm{N}_{2}$} & 400 & $4.7 \pm 2.7$ \\
\cline { 2 - 3 } & 500 & $5.2 \pm 1.5$ \\
\cline { 2 - 3 } & 600 & $45.8 \pm 27.7$ \\
\hline \multirow{3}{*}{$\mathrm{Ar}$} & 400 & $3.3 \pm 1.6$ \\
\cline { 2 - 3 } & 500 & $4.5 \pm 3.6$ \\
\cline { 2 - 3 } & 600 & $16.1 \pm 7.0$ \\
\hline
\end{tabular}

